\title{
Comparative Study between Medical and Surgical Modalities of Treatment of Chronic Allergic Nasal Polypi
}

\author{
Ali Khalaf Mahrous, Mohammed Ahmed El Sharkawy, Abd El Hakeem Abd El Salam Ibrahim* \\ Department of Otorhinolaryngology, Faculty of Medicine, Al-Azhar University, Cairo, Egypt \\ * Corresponding author: Abd El Hakeem Abd El Salam Ibrahim, Tel. No.: (+20) 1007977665, \\ E-mail: doctorah87@gmail.com.
}

\begin{abstract}
Background: Nasal polyposis is a common problem facing the otolaryngologist. Its incidence is estimated to be in the range of 0.2 to $4.3 \%$. It may be associated with other conditions such as bronchial asthma (about $25 \%-30 \%$ of polyposis patients) and Aspirin sensitivity (12\%).

Objectives: The aim of this work was to study the importance of searching and identifying the effect of medical versus surgical modalities in treatment of chronic allergic nasal polyps.

Patients and Methods: Thirty patients with bilateral nasal polyps were enrolled in this study. They were randomly arranged into 2 groups. Group I was treated by functional endoscopic sinus surgery while Group II was treated by local and systemic corticosteroids. The age in Group I ranged from 17 to 66 years with a mean of $42 \pm 16.51$ years while the age in Group II ranged from 19 to 60 years with a mean of $39.4 \pm 11.24$ years. In Group I, 12 patients (80\%) were male while 3 patients (20\%) were female. In Group II, 9 patients $(60 \%)$ were male while 6 patients $(40 \%)$ were female. No past history was found in 18 patients $(60 \%)$ while bronchial asthma was found in 8 patients $(26.67 \%)$ and aspirin sensitivity was found in 3 patients (10\%). Both bronchial asthma and aspirin sensitivity were found in one patient in Group II.

Results: The mean Total nasal symptoms score (TNSS) were $22.33 \pm 1.21$ in Group I and $20.07 \pm 3.31$ in Group II. The mean Total Nasal Polyp Score (TNPS) were $4.67 \pm 0.82$ in Group I and $4.8 \pm 0.862$ in Group II. The mean LundMackay Score (LMS) were $10.87 \pm 0.74$ in Group I and $11 \pm 0.66$ in Group II.

Conclusion: Patients treated by FESS have less residual symptoms, size and severity of residual polyps and rate of recurrence than patients treated medically.

Keywords: Medical and Surgical Modalities, Chronic Allergic Nasal Polyps
\end{abstract}

\section{INTRODUCTION}

Nasal polyposis is a common problem facing the otolaryngologist. Its incidence is estimated to be in the range of 0.2 to $4.3 \%{ }^{(1)}$. It may be associated with other conditions such as bronchial asthma (about $25 \%-30 \%$ of polyposis patients) and Aspirin sensitivity (12\%) (2). The main problem in management of nasal polyposis is its known high incidence of recurrence. Medical treatment is usually the first line of treatment; however, a considerable number of patients may not respond. Patients with associated asthma or acetylsalicylic acid (ASA) sensitivity are known to be more prone to lack of response. Non-responsers generally are candidates for surgical intervention ${ }^{(3)}$.

Nasal polyps (NP) are one of the most common inflammatory mass lesions of the nose, affecting up to $4 \%$ of the population. They present with nasal obstruction, anosmia, rhinorrhea, post nasal drip, and less commonly facial pain. Their etiology remains unclear, but they are known to have associations with allergy, asthma, infection, fungus, cystic fibrosis, and aspirin sensitivity. Surgical treatment has been refined significantly over the past 20 years with the advent of endoscopic sinus surgery (4). Over the last two decades, increasing insights in the pathophysiology of nasal polyposis opens perspective for new pharmacological treatment options, with eosinophilic inflammation, IgE, fungi and Staphylococcus aureus as potential targets ${ }^{(4)}$.

Functional endoscopic sinus surgery is the surgical option (FESS). FESS has evolved over time and many of the surgical procedures currently performed under FESS might be prolonged and accompanied by bleeding. The use of CT guidance and the evolution of the surgical technique have allowed surgeons to become much more aggressive with the scope of their endoscopic procedures ${ }^{(5)}$.

As regard technique of endoscopic endonasal surgery, the Messerklinger technique has been the method of choice. This technique is both a diagnostic and a surgical concept, whereby limited surgery can improve ventilation and drainage of the ostiomeatal complex. A meticulous examination will be done to be able to detect anatomical variants or diseased areas within the ethmoidal region, causing chronic disease to develop. Thereby, a limited surgical approach can restore normal ventilation and drainage in a functional way with little trauma to surrounding structures ${ }^{(6)}$.

The aim of this work was to study the importance of searching and identifying the effect of medical versus surgical modalities in treatment of chronic allergic nasal polyps.

\section{PATIENTS AND METHODS}

This comparative prospective study included a total of 30 patients presented with bilateral nasal 
polyps attending at the Outpatient Clinic of Almokattam Health Insurance Hospital. Approval of the ethical committee and a written informed consent from all the subjects were obtained. This study was conducted between October 2016 to October 2018.

Inclusion criteria: Patients diagnosed with nasal polyposis including all age groups and both genders.

Exclusion criteria:

- Patients with Grade I nasal polyps.

- Patients with fungal sinusitis or underlying neoplasm.

- Patients with unilateral polyp or antrochoanal polyp.

- Patients with cystic fibrosis, ciliary dyskinesia.

- Patients with any condition contraindicating steroids use (diabetes, hypertension, congestive heart failure, osteoporosis, glaucoma, pregnancy, peptic ulcer, tuberculosis, and herpes simplex keratitis),

- Patients with history of previous sinus surgery

- Patients who took corticosteroids orally or parenterally

- Patients with hypertelorism or proptosis.

All patients were subjected to:

A. Complete history taking including personal history (age and sex), complaint of the patient and its duration and past history of bronchial asthma or aspirin sensitivity.

B. Assessment of the disease severity: This was done clinically via TNSS, endoscopically via TNPS and radiologically via LMS. This was done twice; on enrollment and after the end of treatment.

1. Total nasal symptoms score (TNSS: It is a subjective disease-severity rating method. It was used to evaluate clinical disease severity. Patients' symptoms were evaluated based on a questionnaire assessing blocked nose, runny nose, sneezing, nasal itching, hyposmia, and sinonasal pain.

The severity of each individual symptom was assessed with a 7 -point scale: $0=$ no symptoms; 1 to $2=$ mild symptoms (steady symptoms but easily tolerable); 3 to $4=$ moderate symptoms (symptoms hard to tolerate; might interfere with activities of daily living, sleep, or both); and 5 to $6=$ severe symptoms (symptoms so bad that the person could not function virtually all the time). The sum of the individual nasal symptom scores provided the TNSS which ranges from 0-36.

2. Total Nasal Polyp Score (TNPS) Nasal polyp size was assessed by nasal endoscopy and scored on a 0 to 3 scale as follows: $0=$ no polyps; $1=$ mild polyposis (small polyps, extending downward from upper nasal cavity but not below upper edge of the inferior turbinate, causing only slight obstruction); $2=$ moderate polyposis (medium-sized polyps, extending downward from upper nasal cavity and reaching between upper and lower edges of inferior turbinate, causing serious obstruction); and $3=$ severe polyposis (large-sized polyps, extending downward from upper nasal cavity and reaching below lower edge of inferior turbinate, causing total or almost total obstruction). The total nasal polyps score (TNPS) was calculated as the sum of the polyp scores for each side.

3. Lund-Mackay score (LMS): The CT imaging of paranasal sinuses were evaluated using Lund-Mackay staging system. In this system, the right or left sinuses were respectively divided into six portions, including maxillary sinus, anterior ethmoid sinuses, posterior ethmoid sinuses, sphenoid sinus, frontal sinus, and osteomeatal complex. The severity of sinus mucosal inflammation or fluid accumulation was scored as 0 (complete lucency), 1 (partial lucency) or 2 (complete opacity).

a. Unilateral five portions of the sinuses from either the left or the right and one ipsilateral osteomeatal complex were summed to give separate unilaterally total LMS values that could range from 0 to 12 , and the LMS of both sides were summed together to give a total score that ranged from 0-24. It should be noted that mild mucosal thickening without fluid collecting was scored as 0; mild mucosal thickening with fluid collecting causing partial lucency scored as 1; and, moderate or severe mucosal thickening without fluid collecting causing partial lucency, but not complete opacity, scored as 1.

b. In addition, the osteomeatal complex was scored as either 0 (not obstructed) or 2 (obstructed) because it is difficult to describe the osteomeatal complex with any gradation.

\section{Treatment of nasal polyps}

Using tables of random samples/numbers for those submitted to surgery and or medical treatment. Both groups were matched in age and socioeconomic status. Group I received surgical treatment in the form of FESS while Group II received medical treatment.

1. Group I: Patients have undergone functional endoscopic sinus surgery. The procedure was done under general anesthetic. The surgical procedure of functional endoscopic sinus surgery was tailored to each patient according to the different sinus involvement shown on the C.T. scan. Also, merocele packing impregnated with antibiotic ointment was the last step.

\section{Postoperative care}

a. Pack removal on the second day

b. Parentral Broad spectrum antibiotics for one week.

c. Analgesics (as needed)

d. Nasal decongestants three times daily for 5 days,

e. Close observation for postnasal bleeding or other complications.

f. Alkaline nasal douches for at least three weeks.

g. Medical treatment and evaluation of the general condition bronchial asthma).

h. Postoperative visits were weekly for 4 weeks and the follow up has been done monthly for a range of six months to 24 months with a mean of 12 months. 
2. Group II: Patients received intrapolyp steroid injection and oral corticosteroids in addition to local corticosteroid nasal spray.

a. $1 \mathrm{CC}$ of triamcinolone acetonide was used for injection using $3 \mathrm{CC}$ syringe and 21 gauge needle or larger.

b. A mixture of $4 \%$ lidocaine and $0.05 \%$ oxymetazoline was sprayed into the nasal cavity before the injection.

c. Cotton pledgets soaked in the same mixture were then packed into the nasal cavity.

d. 1CC triamcinolone was injected into the polyp with depth of 1-2 mm using 0-degree endoscope.

e. The $1 \mathrm{CC}$ of triamcinolone was shared among the polyps, and not more than $0.5 \mathrm{CC}$ was injected in a single polyp due to the run off.

f. The patients returned at a week interval till they completed a series of three injections.

g. The patients received oral prednisolone for two weeks starting with dose of $1 \mathrm{mg} / \mathrm{kg} /$ day, and decreasing the dose by 20 mg every 5 days.

h. The patients received local steroids nasal spray in the form of fluticasone nasal spray; 2 puffs in each nostril, twice daily for the entire period of follow-up (3 months).

\section{Assessment of outcome}

\section{Perioperative outcome}

- Impact of operative procedure

2. Operative

- Operative time

- Estimated blood loss

- Hospitalization

- Complications

3. Immediate postoperative period

- Symptoms related to the procedure (pain, or frequency and duration of analgesic).

- Pain was assessed by using visual analogue scale (VAS).

\section{RESULTS}

Table (1): Details of the disease after treatment among the patients included in the study

\begin{tabular}{|c|c|c|c|c|}
\hline Details of disease & Group I $(\mathrm{N}=15)$ & Group II (N=15) & Total & p value \\
\hline $\begin{array}{l}\text { Nasal Obstruction } \\
\text { No Obstruction } \\
50 \% \text { obstruction } \\
\text { Complete Obstruction }\end{array}$ & $\begin{array}{c}12(80 \%) \\
2(13.33 \%) \\
1(6.67 \%)\end{array}$ & $\begin{array}{c}3(20 \%) \\
5(33.33 \%) \\
7(46.67 \%)\end{array}$ & $\begin{array}{c}15(50 \%) \\
7(23.33 \%) \\
8(26.67 \%)\end{array}$ & $0.004^{\wedge}$ \\
\hline $\begin{array}{l}\text { Residual Symptom } \\
\text { No residual symptoms } \\
50 \% \text { improvement } \\
\text { No improvement } \\
\end{array}$ & $\begin{array}{c}10(66.67 \%) \\
3(20 \%) \\
2(13.33 \%) \\
\end{array}$ & $\begin{array}{c}1(6.67 \%) \\
6(40 \%) \\
8(53.33 \%) \\
\end{array}$ & $\begin{array}{c}11(36.67 \%) \\
9(30 \%) \\
10(33.33 \%) \\
\end{array}$ & $0.003^{\wedge}$ \\
\hline $\begin{array}{l}\text { TNSS }(0-36) \\
\text { Mean } \pm S D \\
\text { Range }\end{array}$ & $\begin{array}{c}8.4 \pm 3.135 \\
5-15\end{array}$ & $\begin{array}{c}13.7 \pm 3.035 \\
7-18\end{array}$ & & $0.0001 *$ \\
\hline $\begin{array}{l}\text { TNPS }(0-6) \\
\text { Mean } \pm S D \\
\text { Range }\end{array}$ & $\begin{array}{c}1.4 \pm 1.639 \\
0-4\end{array}$ & $\begin{array}{c}3.2 \pm 1.474 \\
0-6\end{array}$ & & $0.004 *$ \\
\hline $\begin{array}{l}\text { LMS }(0-24) \\
\text { Mean } \pm S D \\
\text { Range }\end{array}$ & $\begin{array}{c}4.73 \pm 0.704 \\
4-6\end{array}$ & $\begin{array}{c}7.87 \pm 0.915 \\
6-9\end{array}$ & & $0.0001 *$ \\
\hline
\end{tabular}

Data in $\mathrm{N}(\%)$, mean $\pm \mathrm{SD}$, Significant $\mathrm{p}$ value $\leq 0.05, *$ Student $\mathrm{t}$ test, ${ }^{\wedge}$ Chi-square test 
There was significant difference between group I and group II regarding Nasal Obstruction with p-value $\left(0.004^{\wedge}\right)$, residual symptom with p-value $\left(0.003^{\wedge}\right)$, TNPS $(0-6)$ with p-value $\left(0.0001^{*}\right)$, TNSS $(0-36)$ with p-value $(0.004 *)$ and LMS $(0-24)$ with p-value $\left(0.0001^{*}\right)$.

Table (2): Group I before and after treatment

\begin{tabular}{|c|c|c|c|}
\hline Group I (N=15) & Before & After & p value \\
\hline $\begin{array}{l}\text { Nasal Obstruction } \\
\text { Yes } \\
\text { No }\end{array}$ & $\begin{array}{c}10(66.67 \%) \\
5(33.33 \%)\end{array}$ & $\begin{array}{c}3(20 \%) \\
12(80 \%)\end{array}$ & $0.01 *$ \\
\hline $\begin{array}{l}\text { TNSS }(0-36) \\
\text { Mean } \pm S D \\
\text { Range } \\
\end{array}$ & $\begin{array}{c}22.33 \pm 1.21 \\
14-29 \\
\end{array}$ & $\begin{array}{c}8.4 \pm 3.135 \\
5-15 \\
\end{array}$ & $0.0001^{\wedge}$ \\
\hline $\begin{array}{l}\text { TNPS }(0-6) \\
\text { Mean } \pm S D \\
\text { Range }\end{array}$ & $\begin{array}{c}4.67 \pm 0.82 \\
4-6\end{array}$ & $\begin{array}{c}1.4 \pm 1.639 \\
0-4\end{array}$ & $0.0001^{\wedge}$ \\
\hline $\begin{array}{l}\text { LMS }(0-24) \\
\text { Mean } \pm S D \\
\text { Range }\end{array}$ & $\begin{array}{c}10.87 \pm 0.74 \\
10-12\end{array}$ & $\begin{array}{c}4.73 \pm 0.704 \\
4-6\end{array}$ & $0.0001^{\wedge}$ \\
\hline
\end{tabular}

Data in $\mathrm{N}(\%)$, mean $\pm \mathrm{SD}$, Significant $\mathrm{p}$ value $\leq 0.05,{ }^{*}$ Student $\mathrm{t}$ test, ^ Paired $\mathrm{t}$ test

In Group I, the nasal obstruction improved after FESS (p 0.01). The differences between the means of TNSS, TNPS and LMS before and after treatment in Group I were statistically significant (p 0.0001 each).

Table (3): Group II before and after treatment

\begin{tabular}{|c|c|c|c|}
\hline Group II & Before $(\mathrm{N}=15)$ & After $(\mathrm{N}=15)$ & p value \\
\hline $\begin{array}{l}\text { Nasal Obstruction } \\
\text { Yes } \\
\text { No }\end{array}$ & $\begin{array}{c}11(73.33 \%) \\
4(26.67 \%)\end{array}$ & $\begin{array}{c}12(80 \%) \\
3(20 \%)\end{array}$ & $0.666^{*}$ \\
\hline $\begin{array}{l}\text { TNSS }(0-36) \\
\text { Mean } \pm S D \\
\text { Range }\end{array}$ & $\begin{array}{c}20.07 \pm 3.31 \\
13-25\end{array}$ & $\begin{array}{c}13.7 \pm 3.035 \\
7-18\end{array}$ & $0.0001^{\wedge}$ \\
\hline $\begin{array}{l}\text { TNPS }(0-6) \\
\text { Mean } \pm S D \\
\text { Range }\end{array}$ & $\begin{array}{c}4.8 \pm 0.862 \\
4-6\end{array}$ & $\begin{array}{c}3.2 \pm 1.474 \\
0-6\end{array}$ & $0.001^{\wedge}$ \\
\hline $\begin{array}{l}\text { LMS }(0-24) \\
\text { Meant } S D \\
\text { Range }\end{array}$ & $\begin{array}{c}11 \pm 0.66 \\
10-12\end{array}$ & $\begin{array}{c}7.87 \pm 0.915 \\
6-9\end{array}$ & $0.0001^{\wedge}$ \\
\hline
\end{tabular}

Data in N (\%), mean $\pm \mathrm{SD}$, Significant $\mathrm{p}$ value $\leq 0.05, *$ Student $\mathrm{t}$ test, ^ Paired $\mathrm{t}$ test

In Group II, the nasal obstruction got worsened after medical treatment. The differences between the means of TNSS, TNPS and LMS before and after treatment in Group II were statistically significant (p 0.0001 for TNSS and LMS and 0.001 for TNPS).

Table (4): Recurrence/regression after treatment among the patients included in the study

\begin{tabular}{|l|c|c|c|c|}
\hline Recurrence/Regression & Group I (N=15) & Group II (N=15) & Total & p value \\
\hline Yes & $7(46.67 \%)$ & $13(86.67 \%)$ & $20(66.67 \%)$ & \multirow{2}{*}{$\mathbf{0 . 0 2 0}^{\wedge}$} \\
No & $8(53.33 \%)$ & $2(13.33 \%)$ & $10(33.33 \%)$ & \\
\hline
\end{tabular}

Data in $\mathrm{N}(\%)$, Significant $\mathrm{p}$ value $\leq 0.05,^{\wedge}$ Chi-square test

Table (5): The statistical analysis of the recurrence free survival

\begin{tabular}{|r|c|c|c|}
\hline Survival distributions & Chi-Square & $d f$ & Sig. \\
\hline Log Rank & 7.893 & 1 & $\mathbf{0 . 0 0 5}$ \\
Breslow & 8.698 & 1 & $\mathbf{0 . 0 0 3}$ \\
Tarone-Ware & 8.510 & 1 & $\mathbf{0 . 0 0 4}$ \\
\hline
\end{tabular}




\section{DISCUSSION}

Nasal polyps (NP) are one of the most common inflammatory mass lesions of the nose that affect a large percentage of the population. Although, the reaction is mostly inflammatory, the etiology and pathognesis of such cases still unknown and usually involved multiple etiologies ${ }^{(7)}$.

The management of nasal polyps presents a difficult challenge for the contemporary otorhinolaryngologist. There is still argument about the treatment of nasal polyps, either to use medical treatment or to do surgery ${ }^{(8)}$.

The aim of this work was to compare the efficacy of medical versus surgical modalities in treatment of bilateral nasal polyps. Thirty patients with bilateral nasal polyps were enrolled in this study. They were randomly arranged into 2 groups. Group I was treated by endoscopic sinus surgery while Group II was treated by oral and systemic corticosteroids. Regarding the demographic data and disease details, no significant differences were found between both groups due to random distribution of the patients, thus the results were not biased.

Maximum prevalence of nasal polyps is between 31 and 40 years. They are said to be uncommon under age of 20 years. Incidence of nasal polyps increases with age ${ }^{(9)}$. In this study, the age in Group I ranged from 17 to 66 years with a mean of $42 \pm 16.51$ years while the age in Group II ranged from 19 to 60 years with a mean of $39.4 \pm 11.24$ years.

Regarding sex, a study presented at the 2014 Annual Meeting of the American Academy of Allergy, Asthma and Immunology (AAAAI) found that while women did not appear to have higher rates of prevalence, they did have more severe disease ${ }^{(\mathbf{1 0})}$. In the study of Hulse and colleagues in 2014, they concluded that women with nasal polyps have more severe disease than men ${ }^{(\mathbf{1 1})}$. In our study, 21 patients $(70 \%)$ were male while 9 patients $(30 \%)$ were female.

No past history was found in 18 patients $(60 \%)$ while bronchial asthma was found in 8 patients $(26.67 \%)$ and aspirin sensitivity was found in 3 patients (10\%) which is consistent with Jahromi and Pour study (2012) who found that $31(10.4 \%)$ presented with associated asthma and received treatment, $54(18.2 \%)$ presented with allergic rhinitis ${ }^{(\mathbf{1 2})}$.

Nasal polyps are associated with inflammation of the lining of nasal passages and sinuses that lasts more than 12 weeks (chronic rhinosinusitis). Nasal polyps themselves are soft and lack sensation, so if they're small, they may be asymptomatic. Multiple growths or a large polyp may block nasal passages and sinuses ${ }^{(\mathbf{1 3})}$.

In most case series the average operative time of FESS was 70 minutes which may extend up to 90 minutes or more with surgery in the posterior sinus group or frontal sinus ${ }^{(14)}$. In our study, the mean operative time of FESS was $73.67 \pm 5.16$ min while it was $95.8 \pm 4.4 \mathrm{~min}$ in Ghanem and Elmalt (15). Adhesions form when two moist, opposing surfaces inside the nose heal together, causing a scar. They often form between the septum, which separates the nostrils and one of the wavy structures inside the nose (inferior turbinate). Adhesions can make breathing difficult ${ }^{\left({ }^{16}\right)}$. In our study, adhesions and synechia were found in 5 patients $(33.33 \%)$.

Bleeding and crusting can be considered immediate postoperative complications of FESS. Infection, synechiae formation, and turbinate lateralization are short-term complications. Ostial stenosis, refractory disease, and disease recurrence are long-term complications ${ }^{(17)}$.

Regarding the immediate postoperative complications, intraoperative bleeding is considered an infrequent event in the overall rare major complications. It is usually followed by undesirable sequelae ranging from poor surgical outcome and recurrence of the disease to fatal internal carotid artery injury. Poor visibility adds to the length of the procedure, and a spectrum of minor or major complications ${ }^{(18)}$.

Postoperative pain after FESS during the first postoperative day was moderate. Younger patients reported significantly more pain than did older patients. The pain management was obviously insufficient as patients still reported significantly more from pain on the first postoperative day than patients not demanding for pain relief ${ }^{(\mathbf{1 9})}$.

In our study, the pain during the postoperative period as reported by the patients was mild in 2 patients (13.33\%), moderate in 8 patients $(53.33 \%)$ and severe in 5 patients $(33.33 \%)$.

Synechiae represent a complex problem. Occurring in about $10 \%$ of cases, they are frequent but unapparent in most cases ${ }^{(20)}$. During the first visit, synechiae were found in one patient $(6.67 \%)$ while blood clots were found in 2 patients (13.33\%). Both blood clots and synechia were found in one patient $(6.67 \%)$.

They evaluated how FESS modifies symptom profiles in patients with chronic rhinosinusitis. They found that all the symptoms were significantly improved one year postoperatively. They concluded that FESS is an 
adequate and effective method in treating patients with chronic rhinosinusitis ${ }^{(21)}$.

In Gudiseva and colleague study 2018, they scored nasal symptoms as per TNSS system prior to surgery and 3 months post-surgery. The mean TNSS declined to 2.82 after surgery with a $\mathrm{p}$ value $<0.0001$ indicating a statistically significant improvement in the nasal symptoms post FESS ${ }^{(22)}$. Djukic et al. presented a study of 85 patients who had FESS for NP. At 6 month and 12-month followup, LMS significantly improved to 2.8 and 3.7 respectively, compared to a baseline mean of $8.4^{(23)}$.

The corticosteroids with its potent antiinflammatory effect remained the mainstay in the medical treatment of such disease. This can be in form of sprays, drops, or systemic form. There is a good amount of evidence that topical as well as systemic steroids are effective in reducing the size and symptoms of nasal polyps ${ }^{(8)}$.

Patients who received intranasal steroids showed statistically and clinically significant improvement in nasal symptoms and polyp size when compared to those who received placebo. However, the risk of adverse effects such as epistaxis and local irritation is increased in people taking intranasal corticosteroids. Also, topical steroids need long period to be effective ${ }^{(24)}$.

Some patients didn't respond to topical steroids, and authors explained this as nasal congestion by nasal polyps causes inadequate intranasal distribution of topical steroids. So, application of nasal steroid drops has been proposed to be an alternative delivery method to provide maximum effect in the middle meatal area ${ }^{(25)}$.

Systemic steroids have been shown to be highly effective in chronic sinusitis with polyps. Any consideration of systemic steroids, however, must include screening patients for relative contraindications (diabetes, emotional instability, hypertension, glaucoma, history of tuberculosis), as well as informing them of potential systemic side effects ${ }^{(26)}$.

In addition to well-known steroid administration methods, intrapolyp steroid injection represents a potential method to deliver high concentrations of this anti-inflammatory drug to a local area, thus it is supposed to have more effect than topical steroids ${ }^{(27)}$.

In other words, it is thought to combine the efficacy of oral steroids to the limited side effect of topical steroids. Moreover, the effect of single injection seems to last for 6-8 weeks, largely due to the depot nature of the suspension. Also, the intrapolyp steroid injection is typically an office based procedure that takes approximately 2-3 minutes ${ }^{(28)}$.

After medical treatment, 3 patients had no residual nasal obstruction. The difference between before and after medical treatment was not statistically significant. No residual symptoms were found in one patient. TNSS were $13.7 \pm 3.035$, TNPS were $7.87 \pm 0.915$ and LMS were $11 \pm 0.66$. The differences were statistically significant.

In Stevens et al., 2016 study, there is significant decrease in TNSS, TNPS and Lund-Mackay score of the patients that received injection steroids, with improvement of $82.2 \%$ in TNPS. Comparing to systemic steroids, they found that a slightly higher number of patients improved on oral steroid. But this difference was not statistically different ${ }^{(\mathbf{8})}$.

The effect of steroids on TNPS differed slightly from its effect on Lund-Mackay score, while oral steroids exerted the same effect on both scores. This slight difference can be attributed to that oral steroids exerts their effect diffusely over nasal polyps as well nasal mucosa, while injection, being injected locally into the polyps, acts maximally over the polyps more than the rest of nasal mucoa (26).

In our study, 7 patients $(46.76 \%)$ had recurred nasal polyp after FESS after 6 months. In DeConde and colleagues' study 2017, 363 patients with nasal polyps having undergone FESS were enrolled. A total of 244 (67\%) participants had graded postoperative endoscopies with average of followup of $14.3 \pm 7.0$ months. They found that the recurrence of nasal polyposis 6 months after FESS was $35 \%$ (68/197), compared to 38\% (48/125) after 12 months, and 40\% (52/129) after 18 months ${ }^{(29)}$.

They concluded that polyp recurrence is common after FESS with control of polyps up to 18 months found in approximately $60 \%$ to $70 \%$ of patients ${ }^{(29)}$.

Tuncer and others in 2003 observed that despite the previously mentioned encouraging results representing a great clinical improvement, neither oral steroids nor intrapolyp injection can eradicate the polyps. This raises the concern of recurrence of symptoms and regrowth of polyps, which may necessitate endoscopic surgery later on. But at the same time, it can be the only effective option in some patients that are not fit for surgery and oral steroids are contraindicated for them ${ }^{(\mathbf{3 0})}$.

\section{CONCLUSION}

It could be concluded that patients treated by FESS have less residual symptoms, size and severity of residual polyps and rate of recurrence than patients treated medically. 


\section{REFERENCES}

1. Chaaban M, Walsh E and Woodworth B (2013): Epidemiology and differential diagnosis of nasal polyps. Am J Rhinol Allergy, 27(6): 473-478.

2. Chang J, Chin W and Simon $R$ (2012): Aspirinsensitive asthma and upper airway diseases. Am J Rhinol Allergy, 26(1): 27-30.

3. Moebus $\mathbf{R}$ and Han $\mathbf{J}$ (2012): Immunomodulatory treatments for aspirin exacerbated respiratory disease. Am J Rhinol Allergy, 26(2): 134-140.

4. Rajguru R (2014): Nasal Polyposis: Current Trends. Indian J Otolaryngol Head Neck Surg., 66(1): 16-21.

5. Attri J, Sandhu G, Mohan B, Bala N, Sandhu K and Bansal L (2015): Conflicts in operating room: Focus on causes and resolution. Saudi J Anaesth., 9(4): 457-63.

6. Bandyopadhyay $R$, Biswas $R$, Bhattacherjee $S$, Pandit $\mathbf{N}$ and Ghosh S (2015): Osteomeatal Complex: A Study of Its Anatomical Variation Among Patients Attending North Bengal Medical College and Hospital. Indian J Otolaryngol Head Neck Surg., 67(3): 281-286.

7. Salaria N, Sharma N, Garg U, Saluja S and Agarwal R (2015): Inflammatory Septal Nasal Polyp. Iran J Otorhinolaryngol., 27(81):319-23.

8. Stevens W, Schleimer R and Kern R (2016): Chronic Rhinosinusitis with Nasal Polyps. J Allergy Clin Immunol Pract., 4(4):565-72.

9. Nanda M, Bhatia S and Gupta V (2017): Epidemiology of nasal polyps in hilly areas and its risk factors. Int $\mathbf{J}$ Otorhinolaryngol Head Neck Surg., 3(1):77-81.

10. Schmidt C (2016): Pollen Overload: Seasonal Allergies in a Changing Climate. Environ Health Perspect., 124(4):A70-A75.

11. Hulse K, Stevens W, Tan B, Norton J, Suh L, Kern R et al. (2014): Sex-Specific Differences In Disease Severity In Patients With Chronic Rhinosinusitis With Nasal Polyps. The journal of allergy and cliniccl immunology, 133(2):169.

12. Jahromi A and Pour A (2012): The Epidemiological and Clinical Aspects of Nasal Polyps that Require Surgery. Iran J Otorhinolaryngol., 24(67):75-8.

13. Lee $S$ and Lane A (2011): Chronic Rhinosinusitis as a Multifactorial Inflammatory Disorder. Curr Infect Dis Rep., 13(2):159-68.

14. Weber $R$ and Hosemann W (2015): Comprehensive review on endonasal endoscopic sinus surgery. GMS Curr Top Otorhinolaryngol Head Neck Surg., 14: 8.

15. Ghanem $M$ and Elmalt A (2017): Local anesthesia with sedation versus local anesthesia after general anesthesia for sinus surgery: a randomized trial. Research and Opinion in Anesthesia and Intensive Care, 4(4):18894.

16. Matthias C (2007): Surgery of the nasal septum and turbinates. GMS Curr Top Otorhinolaryngol Head Neck Surg., 6: 10 .
17. Tan $P$ and Poopalalingam $R$ (2014): Anaesthetic Concerns for Functional Endoscopic Sinus Surgery. Proceedings of Singapore Healthcare, 23(3):246-53.

18. Duek I, Sviri G, Amit M and Gil Z (2017): Endoscopic Endonasal Repair of Internal Carotid Artery Injury during Endoscopic Endonasal Surgery. J Neurol Surg Rep., 78(4):e125-e128.

19. Finkensieper M, Poller K, Wittekindt C, Meissner W and Guntinas-Lichius O (2013): Postoperative pain assessment after functional endoscopic sinus surgery (FESS) for chronic pansinusitis. Eur Arch Otorhinolaryngol., 270(1):157-66.

20. Hosemann W and Draf C (2013): Danger points, complications and medico-legal aspects in endoscopic sinus surgery. GMS Curr Top Otorhinolaryngol Head Neck Surg., 12: 6.

21. Netkovski J and Sirgovska B (2006): The impact of functional endoscopic sinus surgery on symptoms in chronic rhinosinusitis. Prilozi., 27(2):167-74.

22. Gudiseva A, Ramaswamy $B$, Singh $R$ and Dalakoti $P$ (2018): Comparative Study of Nasal Symptoms and Pulmonary Function Tests Post FESS in Ethmoidal Polyposis. Indian J Otolaryngol Head Neck Surg., 1:4.

23. Djukic V, Dudvarski Z, Arsovic N, Dimitrijevic M and Janosevic L (2015): Clinical outcomes and quality of life in patients with nasal polyposis after functional endoscopic sinus surgery. Eur Arch Otorhinolaryngol., 272(1):83-9.

24. Şimşek A, Bayraktar C, Doğan S, Karataş M and Sarıkaya Y (2016): The effect of long-term use of intranasal steroids on intraocular pressure. Clin Ophthalmol., 10:1079-82.

25. Bridgeman M (2017): Overcoming barriers to intranasal corticosteroid use in patients with uncontrolled allergic rhinitis. Integr Pharm Res Pract., 6:109-19.

26. Kirtsreesakul V, Wongsritrang $K$ and Ruttanaphol $S$ (2012): Does oral prednisolone increase the efficacy of subsequent nasal steroids in treating nasal polyposis? Am J Rhinol Allergy, 26(6):455-62.

27. Shaikh S, Verma H, Yadav $N$, Jauhari $M$ and Bullangowda J (2012): Applications of Steroid in Clinical Practice: A Review. ISRN Anesthesiology, 2012(985495):11.

28. Coondoo A, Phiske M, Verma S and Lahiri K (2014): Side-effects of topical steroids: A long overdue revisit. Indian Dermatol Online J., 5(4): 416-25.

29. DeConde A, Mace J, Levy J, Rudmik L, Alt J and Smith T (2017): Prevalence of polyp recurrence after endoscopic sinus surgery for chronic rhinosinusitis with nasal polyposis. Laryngoscope, 127(3):550-5.

30. Tuncer U, Soylu L, Aydogan B, Karakus F and Akcali C (2003): The effectiveness of steroid treatment in nasal polyposis. Auris Nasus Larynx, 30(3):263-8. 